\title{
Churg-Strauss Syndrome Presented With Hearing Impairment and Facial Palsy
}

\author{
Jeong-Hyun Byun, MD, Jong-Hoo Lee, MD, In-Sung Choi, MD, PhD
}

\author{
Department of Physical \& Rehabilitation Medicine, Regional Cardiocerebrovascular Center, \\ Chonnam National University Hospital, Chonnam National University Medical School, Gwangju, Korea
}

\begin{abstract}
Churg-Strauss syndrome (CSS) is a rare systemic necrotizing vasculitis. Cranial nerve involvement is very rare in CSS. A 59-year-old woman had complained of both hearing impairments for eight months and left facial palsy for three months. Left facial and cochlear neuropathies were detected in electrodiagnostic studies. Paranasal sinus computed tomography (CT) showed chronic pansinusitis. Chest CT revealed eosinophilic infiltration in the right upper lobe. Tissue biopsy of the right inferior turbinate displayed necrotizing vasculitis with eosinophilic infiltration. She was diagnosed as CSS, based on the presence of eosinophilia, pulmonary infiltration, paranasal sinusitis, and biopsy containing blood vessels with extravascular eosinophils. She was treated with intravenous and oral steroids and azathioprine, showing relatively good prognosis on facial palsy and hearing impairment. We report a very rare case of CSS presented with hearing impairment and facial palsy.
\end{abstract}

Keywords Churg-Strauss syndrome, Facial paralysis, Hearing loss

\section{INTRODUCTION}

Churg-Strauss syndrome (CSS) refers to an autoimmune disease which is characterized by medium and small vessel vasculitis in persons with a history of asthma and allergy [1,2]. It usually involves lung, gastrointestinal tract, skin, heart, and nervous system [1]. Peripheral neuropathy $(\mathrm{PN})$ is a frequent neurological finding [2]. The most common pattern of $\mathrm{PN}$ is mononeuritis multiplex

Received February 11, 2014; Accepted May 7, 2014

Corresponding author: In-Sung Choi

Department of Physical \& Rehabilitation Medicine, Chonnam National University Hospital, 42 Jebong-ro, Dong-gu, Gwangju 501-757, Korea

Tel: +82-62-220-5198, Fax: +82-62-228-5975, E-mail: drchoiis@hanmail.net

(c) This is an open-access article distributed under the terms of the Creative Commons Attribution Non-Commercial License (http://creativecommons. org/licenses/by-nc/3.0) which permits unrestricted noncommercial use, distribution, and reproduction in any medium, provided the original work is properly cited.

Copyright (C) 2014 by Korean Academy of Rehabilitation Medicine as shown in $36.1 \%-71.8 \%$ of CSS patients [3]. However, cranial nerve involvement has been rarely reported [3,4], and the involvement of seventh and eighth cranial nerves has not been reported, at least, not yet in Korea [5]. We experienced a very rare case of CSS with an initial presentation of hearing impairment and facial palsy. Therefore, we hereby report this case with a review of the literature.

\section{CASE REPORT}

A 59-year-old woman was admitted to our hospital for both hearing impairments, both nasal obstructions, and tinnitus for eight months and left facial palsy for three months. Both nasal obstructions were accompanied by anosmia and saddle nose. The hearing impairment was more severe in the left side. She displayed the left facial palsy of grade III on House-Brackmann facial nerve grading system (HBFNGS). She had no medical history of hy- 
pertension, diabetes mellitus, pulmonary tuberculosis, or hepatitis. About eight months previously, she was treated for otitis media with effusion.

On otorhinolaryngological examination, the ear drums were free, but both nasal cavities were filled with crust. The laboratory data on admission revealed eosinophilia (13.1\%), anemia (hemoglobin $9.5 \mathrm{~g} / \mathrm{dL}$, hematocrit $31.2 \%$, iron $5 \mu \mathrm{g} / \mathrm{dL}$, TIBC $84 \mu \mathrm{g} / \mathrm{dL}$, and ferritin 202.04 $\mathrm{ng} / \mathrm{mL})$, thrombocytosis $\left(669,000 / \mathrm{mm}^{3}\right)$, markedly el-

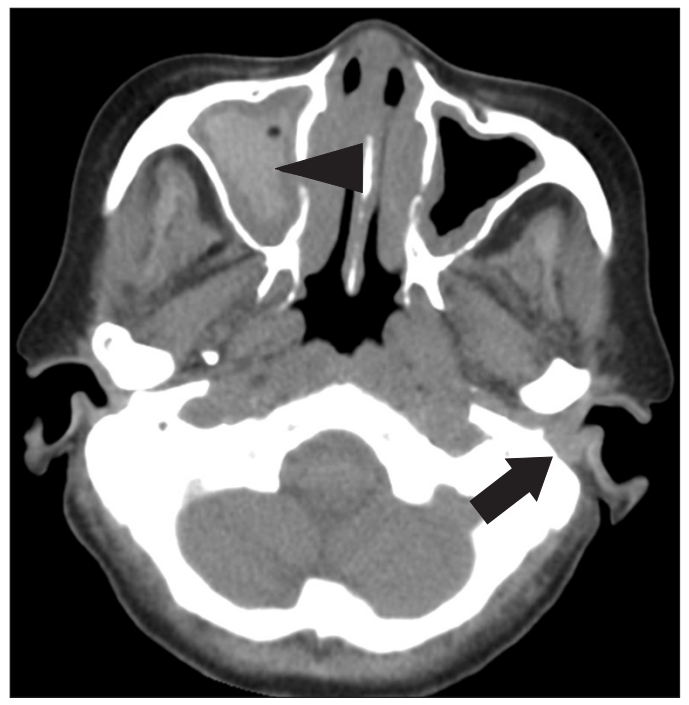

Fig. 1. Paranasal sinus computed tomography showed chronic pansinusitis (arrow head) and diffuse soft tissue thickening (arrow).

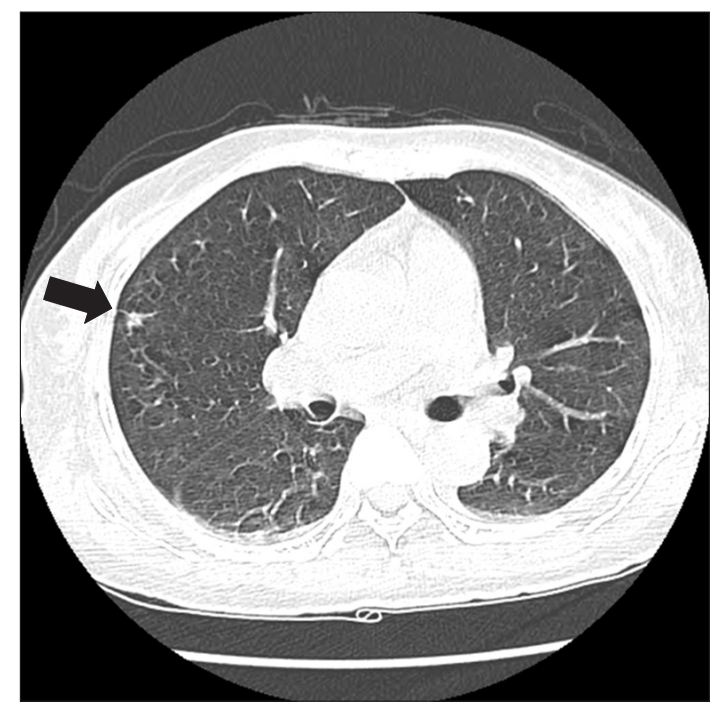

Fig. 2. Chest computed tomography displayed a nodule with surrounding ground-glass opacity in the right upper lobe (arrow). evated C-reactive protein $(10.60 \mathrm{mg} / \mathrm{dL})$, erythrocyte sedimentation rate $(120 \mathrm{~mm} / \mathrm{hr})$, and rheumatoid factor (201.7 IU/mL). The myeloperoxidase antineutrophil cytoplasmic antibody (MPO-ANCA) was positive. Antinuclear antibody (ANA) and ANCA (proteinase 3) were negative. Venereal disease research laboratory (VDRL) was nonreactive.

Paranasal sinus computed tomography (CT) showed chronic pansinusitis, diffuse soft tissue thickening, and enhancement at the left external auditory canal, as shown in Fig. 1. Chest CT displayed eosinophilic infiltration in the right upper lobe, as shown in Fig. 2. Pulmonary function test showed restrictive pattern and reversibility to bronchodilator. Pure tone audiogram (PTA) showed severe bilateral sensorineural hearing loss (SNHL) of 87 $\mathrm{dB}$ on the left side and $73 \mathrm{~dB}$ on the right side. In brainstem auditory evoked potentials (BAEPs), latencies of wave I, III, and V were delayed in the left ear stimulation while they were not delayed in the right ear stimulation. Interpeak latency of wave I-V was within normal range in both ear stimulations. Motor nerve conduction study of facial nerve displayed no evoked compound muscle action potentials (CMAPs) in the left nasalis muscle and decreased amplitudes of CMAPs in the left orbicularis oculi and orbicularis oris muscles. In blink reflex, there were not evoked ipsilateral R1 and R2 latencies on the left supraorbital stimulation and contralateral R2 latency on the right supraorbital stimulation. Unfortunately, we could not examine the involvement of peripheral nerves.

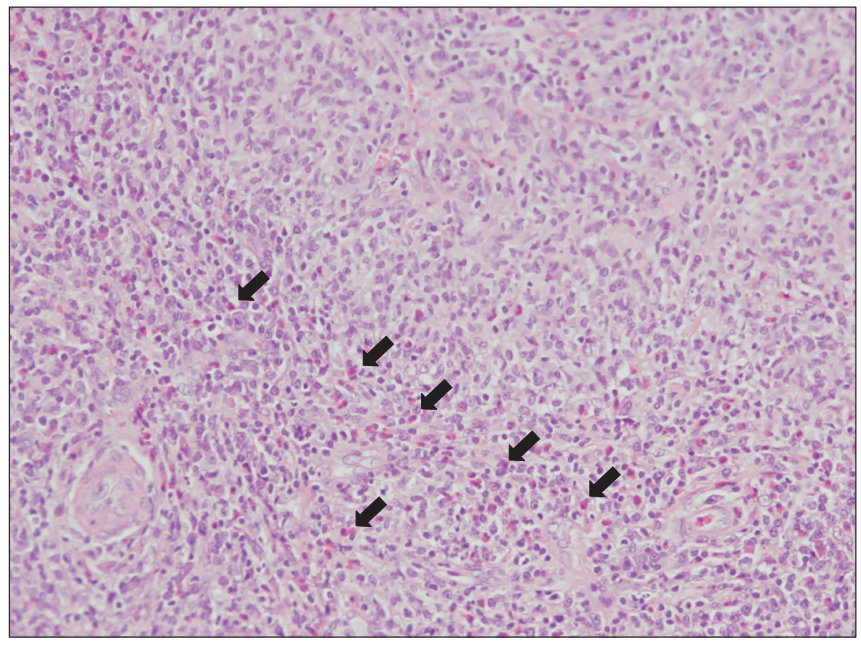

Fig. 3. Tissue biopsy of right inferior turbinate revealed eosinophilic infiltration (arrows). 
Tissue biopsy from the right inferior turbinate revealed necrotizing vasculitis with eosinophilic infiltration, as shown in Fig. 3. According to the 1990 American College of Rheumatology (ACR) criteria [6], she was diagnosed as CSS based on the presence of eosinophilia, pulmonary infiltration, paranasal sinusitis, and biopsy containing blood vessels with extravascular eosinophils.

She was initially treated with intravenous prednisolone of $125 \mathrm{mg} /$ day for two weeks, then oral prednisolone of $50 \mathrm{mg} /$ day tapering off for two weeks, and cyclophosphamide $50 \mathrm{mg}$ daily for six months. She received rehabilitation, including facial remedial massage, infrared, and electrical stimulation for a week. She displayed gradual improvement of eosinophilia, hearing impairment, and facial palsy but not nasal obstruction. Three months later, the left facial palsy was more improved to grade I on HBFNGS. Follow-up PTA recorded improvement on both sides, to $55 \mathrm{~dB}$ on the left side and $35 \mathrm{~dB}$ on the right side. However, she has complained of general weakness, weight loss, and tingling sensation of extremities during the follow-up period.

\section{DISCUSSION}

CSS is a rare systemic disease characterized by inflammation of blood vessels and resulting in different degrees of organ dysfunction [1,2]. According to the 1990 ACR criteria [6], our case was diagnosed as CSS by fulfilling four out of six criteria.

Common clinical manifestations of CSS might be different, depending on the timing of diagnosis and stages of disease. The most frequent clinical manifestations are respiratory tract involvement [1]. In a recent study of the French Vasculitis Study Group cohort, the most common manifestations were PN followed by eye, nose, and throat (ENT) signs [7]. The most common manifestations at diagnosis were weight loss, mononeuritis multiplex, nonerosive sinusitis/polyposis, skin lesions, and lung infiltrates [7]. Cranial nerve involvement was not common, showing an incidence of $3.1 \%-14 \%$ [8]. Cranial nerves were variously involved, and the most common symptom was ischemic optic neuropathy $[2,8]$. Facial palsy or hearing impairment in CSS patients was rarely reported in other countries $[2,4,7,9]$. However, the involvement of seventh and eighth cranial nerves has not been reported, at least, not yet in Korea [5].
Otologic manifestations, such as otitis media, ear discharge, and SNHL, were not common; however, those symptoms occurred during advanced stages [7]. Our patient initially showed symptoms of secretory otitis media, nasal obstruction, and anosmia, followed by hearing impairment and facial palsy. In our case, CSS might be diagnosed in an advanced stage.

Although the exact mechanism of SNHL associated with CSS is not exactly known, arteritis of internal auditory artery may result in ischemia of vestibulocochlear nerve [9]. Paresthesia and motor weakness for our patient during the follow-up period may suggest the presence of PN. We think that vasculitic neuropathy, including cranial nerve involvement, may explain her general and cranial symptoms.

For the assessment of severity and prognosis of CSS, the 1996 Five-Factor Score (FFS) was used [10]. In this case, FFS was 0 , suggesting relatively good prognosis. Her cranial nerve symptoms were improved by medications. However, she has continuously complained of systemic symptoms during the follow-up period. It is probably because she was already in an advanced stage at the time of initial diagnosis.

We report a case of CSS that displayed hearing impairment and facial palsy as a very rare initial presentation. If ENT involvement is present, systemic necrotizing vasculitis should be considered, despite the rarity of the disease, and an additional evaluation should be performed.

\section{CONFLICT OF INTEREST}

No potential conflict of interest relevant to this article was reported.

\section{REFERENCES}

1. Churg J, Strauss L. Allergic granulomatosis, allergic angiitis, and periarteritis nodosa. Am J Pathol 1951;27:277-301.

2. Wolf J, Bergner R, Mutallib S, Buggle F, Grau AJ. Neurologic complications of Churg-Strauss syndrome: a prospective monocentric study. Eur J Neurol 2010; 17:582-8.

3. Sehgal M, Swanson JW, DeRemee RA, Colby TV. Neurologic manifestations of Churg-Strauss syndrome. Mayo Clin Proc 1995;70:337-41. 
4. Ozaki Y, Tanaka A, Shimamoto K, Amuro H, Son Y, Ito T, et al. Effective intravenous immunoglobulin therapy for Churg-Strauss syndrome (allergic granulomatous angiitis) complicated by neuropathy of the eighth cranial nerve: a case report. J Med Case Rep 2012;6:310.

5. Oh MJ, Lee JY, Kwon NH, Choi DC. Churg-Strauss syndrome: the clinical features and long-term follow-up of 17 patients. J Korean Med Sci 2006;21:265-71.

6. Masi AT, Hunder GG, Lie JT, Michel BA, Bloch DA, Arend WP, et al. The American College of Rheumatology 1990 criteria for the classification of Churg-Strauss syndrome (allergic granulomatosis and angiitis). Arthritis Rheum 1990;33:1094-100.

7. Comarmond C, Pagnoux C, Khellaf M, Cordier JF, Hamidou M, Viallard JF, et al. Eosinophilic granuloma- tosis with polyangiitis (Churg-Strauss): clinical characteristics and long-term followup of the 383 patients enrolled in the French Vasculitis Study Group cohort. Arthritis Rheum 2013;65:270-81.

8. Tsuda H, Ishikawa H, Majima T, Sawada U, Mizutani T. Isolated oculomotor nerve palsy in Churg-Strauss syndrome. Intern Med 2005;44:638-40.

9. Ishiyama $\mathrm{A}$, Canalis RF. Otological manifestations of Churg-Strauss syndrome. Laryngoscope 2001; 111:1619-24.

10. Guillevin L, Pagnoux C, Seror R, Mahr A, Mouthon L, Le Toumelin P, et al. The Five-Factor Score revisited: assessment of prognoses of systemic necrotizing vasculitides based on the French Vasculitis Study Group (FVSG) cohort. Medicine (Baltimore) 2011;90:19-27. 